\title{
Direct Fluorescent Antibody Test
}

National Cancer Institute

\section{Source}

National Cancer Institute. Direct Fluorescent Antibody Test. NCI Thesaurus. Code C53467.

An immunoassay in which a fluorescent-labeled antibody binds directly to a target antigen. 